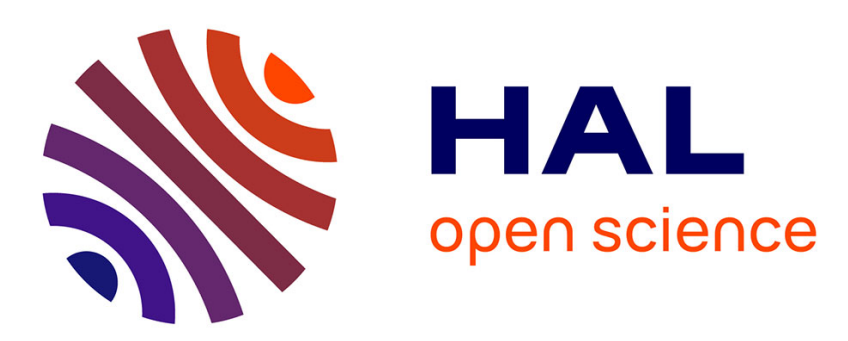

\title{
Energy distribution in the squeezing of particles in concentrated suspension
}

\author{
Patrice Estellé, Y. Mélinge, Arnaud Perrot, Christophe Lanos
}

\section{To cite this version:}

Patrice Estellé, Y. Mélinge, Arnaud Perrot, Christophe Lanos. Energy distribution in the squeezing of particles in concentrated suspension. Granular Matter, 2007, 10 (2), pp.81-87. 10.1007/s10035007-0076-9 . hal-00664419

\section{HAL Id: hal-00664419 https://hal.science/hal-00664419}

Submitted on 30 Jan 2012

HAL is a multi-disciplinary open access archive for the deposit and dissemination of scientific research documents, whether they are published or not. The documents may come from teaching and research institutions in France or abroad, or from public or private research centers.
L'archive ouverte pluridisciplinaire HAL, est destinée au dépôt et à la diffusion de documents scientifiques de niveau recherche, publiés ou non, émanant des établissements d'enseignement et de recherche français ou étrangers, des laboratoires publics ou privés. 


\title{
Energy distribution in the squeezing of particles in concentrated suspension
}

\author{
PATRICE ESTELLÉ (®)
}

LGCGM, Département Matériaux et Thermique de l'Habitat, Institut National des Sciences Appliquées, 20 avenue des Buttes de Coësmes, CS 14315, 35043 Rennes, France

Email : patrice.estelle@insa-rennes.fr

Tel : +33(0) 223234056

Fax : +33(0) 223238448

\section{YANNICK MÉLINGE}

LGCGM, Département Matériaux et Thermique de l'Habitat, Institut National des Sciences Appliquées, 20 avenue des Buttes de Coësmes, CS 14315, 35043 Rennes, France

Email : yannick.melinge@insa-rennes.fr

Tel : +33 (0) 223238550

\section{ARNAUD PERROT}

LGCGM, Département Matériaux et Thermique de l'Habitat, Institut National des Sciences Appliquées, 20 avenue des Buttes de Coësmes, CS 14315, 35043 Rennes, France

Email : arnaud.perrot@ens.insa-rennes.fr

Tel : +33 (0) 223238200

\section{CHRISTOPHE LANOS}

LGCGM, Département Matériaux et Thermique de l'Habitat, Institut Universitaire Technologique, rue du Clos Courtel, BP 90422, 35704 Rennes Cedex 7, France

Email : Christophe.Lanos@univ-rennes1.fr

Tel : +33 (0) 223234067

\section{ABSTRACT}

In the present work, the squeeze flow geometry is used to investigate the properties of concentrated suspensions. The suspensions consist on hard glass spherical particles dispersed in a viscoplastic fluid. With such a material, following the solid volume fraction, the material rheological behaviour ranges from purely viscoplastic fluid to granular media. During the squeezing action, the material structure evolves with energy variation due to particle displacement and interaction. The goal of our study is to identify the effect of energy evolution on the flow properties of suspensions and detect granular contact evolution. 
The proposed study consists on an energy approach based on the analysis of the global squeeze force and sample height with time. The squeeze force is decomposed in a combination of an average force component and a fluctuating one. This local fluctuating component is investigated from Fourier analysis as a function of solid volume fraction and compression velocity. Results show the evolution of the energy distribution during compression and allow the flow regime modification to be evaluated.

KEYWORDS: Suspensions, squeezing flow, energy approach, particles

\section{Introduction}

Suspensions containing solid particles, such as fibers, spherical and non-spherical elements, are commonly encountered in industrial processes and products. So, the suspension properties have to be investigated as a function of solid volume fraction, particle shape or deformability, particle size distribution, specific surface area of particle, as well as suspended fluid properties. As shown in [1], the flow of concentrated suspensions or granular media is complex and largely influenced by the physical properties of particles, the interaction variety between particles and shear rate. This may induce different flow regimes. The behaviour of concentrated suspensions and granular mixtures is generally investigated from simulations and rheological measurements. It appears that the squeezing flow is a practical geometry to determine the material properties of a wide range of materials, from soft fluids to highly concentrated pastes [2]. In such a flow, material is deformed between two circular parallel plates, as shown Fig.1, and squeezed out radially with both extensional and shear deformations. There is an extensive body of literature on the use of squeeze flow for rheological characterization of materials. There have been many studies of the response of squeezing force depending on fluid rheological behaviour and material-plate boundary condition [3-10]. So, squeeze flow has been previously used to study spherical particles suspended in Newtonian [11] and shear-thinning fluids [12]. It was found in these works that two main flow regimes appear. At low strain rate, viscous flow is predominant. At higher strain rate, solid-fluid separation is induced and the particles skeleton behaves as a deformable porous media. The relative liquid-solid motion of pastes with squeeze flow geometry has also been investigated from numerical analysis [13] and both theoretical and experimental point of view $[14,15]$. The frictional behavior of cement-based materials has been highlighted from squeezing experiments [16], showing also fluid drainage through the granular skeleton and sample hardening at low strain rate. 
The squeezing flow is presently used to investigate the behavior of an idealized system of smooth hard spheres dispersed in a yield stress colloidal gel. Due to the spherical glass particle addition in the gel, the rheological behaviour of the suspension evolves according to the solid volume fraction of particles. Also, the material rheological behaviour ranges from purely viscoplastic fluid to lubricated granular media and purely granular media. The increase of particle concentration leads to a frictional behaviour of the suspensions. During the squeezing action, the material structure evolves with energy variations due to particle displacement, interaction and fracture. Also, we focus here on the energy approach based on the analysis of the global squeeze force of suspension that is decomposed in a combination of an average force component and a fluctuating one. Results are discussed in terms of evolution of the power spectral density of fluctuating force component which is obtained from Fourier analysis. Fourier analysis was previously used in rheology, in particular to investigate the viscoelastic properties of fluids in oscillatory measurements [17-19]. As mentioned in [20], the behaviour of granular media consists in the elastic and plastic deformation of particles and their rearrangement during the flow with frictional-collisional contribution. The solid volume fraction of suspensions considered ranges from $48.5 \%$ to packing value. Squeeze flow experiments are performed using a texture analyser with different compression speeds. Attention is here concentrated on the effects of changing the volume fraction of particles and compression speed with an attempt to detect flow regime transition and concentration evolution of the flowing suspension.

FIGURE 1

\section{Material and experiments}

Suspensions: The suspensions consisted of hard glass spherical particles dispersed in translucent colloidal gel. For each test, we prepared a suspension by adding a given volume of spheres to the gel. The suspension was mixed by hand at ambient temperature $\left(\sim 20^{\circ} \mathrm{C}\right)$. The glass particles have a smooth surface and the volume median diameter of particles ranges from 0.85 to $1 \mathrm{~mm}$. The particle size distribution of spheres is given in Figure 2. The particle density is approximatively $2670 \mathrm{~kg} \cdot \mathrm{m}^{-3}$. The mass fraction of particles according to gel varied between 200 and $1000 \%$. The volume fraction of particles in the suspensions investigated varied between $48.5 \%$ to packing value. The theoretical maximum packing volume fraction of monodisperse spheres is $74 \%$. Experimental observations have shown that dense random 
packing is close to $64 \%$ [21]. Here, experiments lead to obtain theoretical packing value for a mass fraction of particles according to gel equals to $600 \%$. Mixture analysed with higher mass fraction keep packing value, but gel does not fill all the voids between particles and the probability of direct sphere contact is enhanced.

FIGURE 2

The composition of the colloidal gel mainly includes water, PVP/VA copolymer, polyquaternium-11, acrylates C10-30, alkyl acrylate crosspolymer, niacinamide, DMDM hydantoin, aminomethyl propanol. It density is $1260 \mathrm{~kg} . \mathrm{m}^{-3}$. The rheological behaviour of the colloidal gel in terms of the evolution of its shear stress as a function of shear rate is described on Fig.2. The rheological behaviour was determined using a Gemini 150 Malvern rheometer equipped with smooth plate-plate geometry of $40 \mathrm{~mm}$ in diameter and $2 \mathrm{~mm}$ in gap. As shown Fig. 2, the gel is a viscoplastic fluid throughout the whole shear rate investigated. So, in the shear rate range considered, the fluid can be modelled as a general Herschel-Bulkley fluid:

$$
\tau=\tau_{0}+\mu \cdot \dot{\gamma}^{n} \text { for } \tau>\tau_{0}
$$

where the shear-thinning index $\mathrm{n}$ is 0.45 , the consistency $\mu$ is $38.6 \mathrm{~Pa} . \mathrm{s}^{0.45}$ and the yield stress $\tau_{0}$ is $58.3 \mathrm{~Pa}$.

FIGURE 3

Squeezing flow: The suspensions are squeezed out in constant contact area between the sample and two circular parallel rough plates, to reduce slippage, mounted on a texture analyser [22]. Plates are made of steel and roughness is obtained from concentric grooves of $1 \mathrm{~mm}$ in height and gap, manufactured at the plate surface. In our squeeze flow geometry, described in Fig.1, the squeezing action is realised by moving the upper plate at constant velocity, with the lower one remaining motionless. Consequently, the squeeze force and the sample gap vary with time and are recorded for two fixed velocities, 0.1 and $8 \mathrm{~mm} . \mathrm{s}^{-1}$, with a sampling rate of $400 \mathrm{~Hz}$. The initial height of the squeezed volume is $15 \mathrm{~mm}$. The radius of the plates is $25 \mathrm{~mm}$. The squeeze flow experiments are performed at ambient temperature and stopped when the load of the texture analyser reached $250 \mathrm{~N}$ to avoid a significant deformation of the particles. Tests are carried out in two replicates.

With heterogeneous fluids, the height sample variation during compression reduces distance between particles. Consequently, particle contact and interaction increase during test and squeeze force measurement may be used to investigate this phenomenon. 
As example, Figure 4 represents the evolution of the squeeze force as a function of sample gap on plate radius ratio, $\mathrm{h} / \mathrm{R}$, for different suspension concentrations in the case of a $8 \mathrm{~mm} \cdot \mathrm{s}^{-1}$ compression velocity. This result shows firstly that, as expected, the squeezed sample thickness for a $250 \mathrm{~N}$ compression load depends on volume fraction of particles. Figure 4 shows also that highly concentrated suspensions tends to behave similarly, with a fluctuating squeeze force at low sample gap due to particle displacement and interaction, in which a significant relative solid-fluid motion is present. It is also shown that the lower concentrated suspension (48.5\%) behaves as the suspended fluid. This leads to envisage that the $48.5 \%$ concentrated suspension behaves as a homogenous fluid, in which particles do not interact at high sample thickness.

The transition between these two flow conditions, homogeneous and heterogeneous flow, is obtained for the $65.3 \%$ concentrated suspension. In the following section, we investigate the flow behaviour of suspensions from an energy approach. Energy dissipation during compression is deduced from Fourier analysis of squeeze force signal.

FIGURE 4

\section{Energy dissipation in the squeezed volume: spectral density approach}

As mentioned above, in order to evaluate energy variation due to particle displacement and interaction, we have considered the following approach. The global squeeze force signal is decomposed in $\mathrm{n}$ successive windowed signals of duration $\mathrm{T}$. It is assumed that each of these windowed signals of the squeeze force is a linear combination of an average force component and a fluctuating one, as shown equation (1).

$$
F(t)=\bar{F}(t)+F^{\prime}(t)
$$

where $F$ is the squeeze force, $\bar{F}$ is the average force component between $\mathrm{t}$ and $\mathrm{t}+\mathrm{T}$ which is assumed to be a time linear function as $\bar{F}(t)=a t+b$, and $F^{\prime}$ denotes the fluctuating part of the force during the time $\mathrm{T}$, with $\bar{F}^{\prime}=\frac{1}{T} \int_{0}^{T} F^{\prime} d t=0$.

The energy distribution included in the squeeze force signal during the compression is identified using the power spectral density, denoted PSD later, and obtained from Fourier analysis. The PSD is calculated via the magnitude modulus of the FFT of the windowed fluctuating force signal, as follows: 


$$
\begin{gathered}
F F T\left(F^{\prime}\right)=\int_{0}^{T} F^{\prime}(t) \cdot e^{J \omega t} d t \\
P S D=\left\|F F T\left(F^{\prime}\right)\right\|
\end{gathered}
$$

with $\omega=2 \pi f$ and the frequency $f=1 / T$.

The Fourier transform technique is a commonly used method to obtain a quantitative measure of fluctuations in a periodic curve. It is presently applied to the fluctuating force component in the time domain to convert it to the frequency domain. The PSD is used to characterise the nature of the energy distribution in the frequency domain. The Fourier analysis allows the evaluation of properties that are otherwise difficult to be appreciated with time domain analysis.

\subsection{Preliminary results}

To apply the energy approach and evaluate how the energy in the signal is distributed among frequency, the input data have to be windowed prior to the FFT computation. The main role of the window $\mathrm{T}$ is to evaluate the sample gap influence on PSD evolution. There is a natural tendency to use a large value of $\mathrm{T}$ in order to obtain large and suitable frequency range. It also exists a compromise between the number of points in the investigated file and the sampling rate that is the rate at which the data points are being measured during experiments. The condition $\bar{F}^{\prime}=0$ and the accuracy of the regression coefficient linked to the linear evolution of the average force component have also be ensured. In consequence, we have envisaged three values of T: 50, 100 and 256 points. Influence of chosen window value is illustrated by Figure 5 (a,b,c) considering a $48.5 \%$ concentrated suspension squeezed at $0.1 \mathrm{~mm} . \mathrm{s}^{-1}$. For these figures, it was found that the choice of window size does not greatly affect the shape of the resulting spectrum. PSD evolution is similar with the different $\mathrm{T}$ values, but the frequency range is extended up to low frequencies with the larger window value. It can be noted that increasing the window size induces higher PSD values. As a consequence, results will be expressed using $\mathrm{T}=256$ points.

\section{FIGURE 5}

Figure 6 represents the fluctuating force component of a $48.5 \%$ concentrated suspension squeezed at $0.1 \mathrm{~mm} . \mathrm{s}^{-1}$. This figure clearly shows the periodic signal of this component. At high sample gap, the magnitude of fluctuating force component is quite constant due to the rearrangement of particles only, but integrates also experimental noisy due to texture analyser. 
It can be seen that at low sample gap, when plates are close, magnitude of fluctuating force evolves and increases due to particle interaction and collision with the plates.

FIGURE 6

In such a study, it is also necessary to distinguish the energy contribution of the flow and the instrument. The energy contribution linked to the instrument is due to the drive motor and includes the compression speed effect [22]. Actually, the upper plate displacement, without sample contact, induces noises. Figure 7 describes the PSD evolution of a test run with no sample. This shows that the equipment used for the experiments produces rays pattern with several high energy peaks at approximately 40, 80 and $120 \mathrm{HZ}$ for both compression speeds investigated. This result allows the following remark to be made. Similar energy peaks appear when suspensions are squeezed out (see figure 5 and 8). So, it can be deduced that energy peaks due to particle displacement and interaction appear at low frequencies as it will be shown.

FIGURE 7

Comparison of figures 8 (a) and (b) shows that once suspension is flowing, PSD increases during time with ray pattern. At the compression test end, squeeze force increases and the PSD value is enlarged, see figure 8(b). It is noted that PSD evolution becomes complex with an energy contribution at low frequencies. This contribution is attributed to particle contact and interaction. As shown before, increasing solid volume fraction leads to PSD value increasing. It is finally noted that our approach do not distinguish the energy contribution due to extensional flow in the symmetry axis of the plates and shear flow close to the plates.

FIGURE 8 (A)

FIGURE 8 (B)

\subsection{Experimental results and discussion}

In this section, we investigate the influence of particle concentration and compression velocity on the energy evolution during the squeezing of suspensions. Results are expressed considering a mean value of PSD, noted $\mathrm{PSD}_{\mathrm{a}}$ (see equation 5) which is obtained as the area of PSD curve for the frequency range divided by $f_{\max }\left(f_{\max }=200 \mathrm{~Hz}\right.$, one half of sampling 
rate). It is represented in function of an averaged single point value of sample height, for each window $\mathrm{T}$, denoted $\mathrm{h}_{\mathrm{a}}$.

$$
P S D_{a}=\frac{1}{f_{\max }} \int_{0}^{f_{\max }} P S D(f) d f
$$

Figure 9 reports the $\mathrm{PSD}_{\mathrm{a}}$ evolution of the suspension as a function of $\mathrm{h}_{\mathrm{a}}$ for the different particle concentration and the $8 \mathrm{~mm} . \mathrm{s}^{-1}$ compression velocity. An increase of $\mathrm{PSD}_{\mathrm{a}}$ for decreasing averaged sample height $h_{a}$ can be seen for each suspension. This behaviour, which is more pronounced for dilute suspensions, was expected and clearly explained by the displacement of the particles during the compression and their interaction at low sample gap. So, energy dissipation is predominant when the particles interact and agglomerate due to upper plate displacement. It is also shown that energy evolution is similar with high concentrated suspensions $(73.9 \%, 79.3 \%$ and $82.5 \%)$. This can be explained as follows: during compression, sample height decreases and a part of suspension is squeezed out the plates. A critical sample thickness appears when flow-induced heterogeneity is predominant. Squeezed suspension consists also mainly on granular mixture, where particle concentration is not influent, rather than concentrated suspension. In addition, the similar results obtained with $73.9 \%, 79.3 \%$ and $82.5 \%$ concentrated suspensions suggest that energy activity with $79.3 \%$ and $82.5 \%$ suspensions should be obtained from a fixed packing value which is close to the theoretical packing value. Figure 9 shows also that the energy dissipation is similar for the 48.5\% concentrated suspension and the suspended gel. It is concluded in this case, that particles do not interact because the suspension is very dilute. The PSDa evolution is more important due to the contact of the plates at the test end. As observed from a general point of view in Figure 2, the transition between granular mixture and dilute suspension is obtained with the $65.3 \%$ concentrated suspension, which is close to dense random packing [21].

FIGURE 9

Therefore, it can be seen, that for a fixed $\mathrm{PSD}_{\mathrm{a}}$ value, a critical thickness appears and this criteria increases with mass concentration increasing. Energy dissipation of suspensions may be similar and obtained for different sample height following the particle concentration. Influence of compression velocity is investigated considering the $\mathrm{PSD}_{\mathrm{a}}$ evolution as a function of $h_{\mathrm{a}}$ for the $48.5 \%$ and $82.5 \%$ particle concentration with a $0.1 \mathrm{~mm}^{-1} \mathrm{~s}^{-1}$ compression velocity. Results are described by Figure 10. As previously obtained, an increase of $\operatorname{PSD}_{\mathrm{a}}$ for decreasing averaged sample height $h_{a}$ can be seen for both suspensions. The critical thickness is also quite identical for both suspensions considered here. It is also shown that energy 
evolution is more important with the higher concentrated suspension. We noted that $\mathrm{PSD}_{\mathrm{a}}$ value are lower that in the case of the $8 \mathrm{~mm} . \mathrm{s}^{-1}$ compression velocity. Due to the lower compression velocity presently used, particles moves slowly with lubricated contact rather than forced contact as with high compression velocity. In consequence, energy distribution is less important.

FIGURE 10

\section{Conclusions}

An experimental investigation of the behaviour of an idealized system of spheres dispersed in a yield stress fluid in constant velocity squeeze flow geometry was presented from an energy approach. The squeeze force was decomposed in average and fluctuating component. The energy distribution included in the squeeze force signal during the suspension compression was identified from the power spectral density of fluctuating force component. In particular, we considered the influence of particle concentration and compression velocity. It was found that energy dissipation is predominant for both high concentrated suspensions and compression velocity due to the interaction and forced contact between particles. However, from a critical volume fraction of particles, energy distribution is quite identical for all the suspensions investigated. This could be explained by the fact that packing solid volume fraction is reached. On the other hand, low compression speed has the opposite effect. In this case, energy evolution is less important during the compression due to the slow movement of particles and lubricated contact between each particle.

An interesting problem, which may be now envisaged, is the energy distribution in squeezing flow of polydisperse suspension of spheres and non-spherical particles in suspension.

\section{References}

[1] Coussot P., Ancey C.: Rheophysical classification of concentrated suspensions and granular pastes, Phys. Rev. E59, 4445-4457 (1999)

[2] Engmann J., Servais C., Burbidge A.S.: Squeeze flow theory and applications to rheometry - a review, J. Non-Newtonian Fluid Mech. 132, 1-27 (2005)

[3] Bird R.B, Armstrong R.C, Hassager O., Dynamics in polymeric liquids vol.1, 2d ed, John Wiley \& Sons, New York (1987)

[4] Macosko C.W., Rheology principle, measurements, and applications, VCH Publishers, New York (1994)

[5] Sherwood J.D., Durban D., Squeeze flow of power law viscoplastic solid, J. Non-Newtonian Fluid Mech. 62, 35 (1996)

[6] Adams M.J., Aydin I., Briscoe B.J., Sinha S.K., A finite element analysis of the squeeze flow of an elasto-viscoplastic paste material, J. Non-Newtonian Fluid Mech. 71, 41 (1997) 
[7] Huilgol R.R., Variational principle and variational inequality for a yield stress fluid in the presence of slip, J. NonNewtonian Fluid Mech. 75, 231 (1998)

[8] Lawal A., Kalyon D.M., Compressive squeeze flow of generalized Newtonian fluids with apparent wall slip, Intern. Polymer Processing 15, 63 (2000)

[9] Smyrnaios D.N., J.A. Tsamopoulos J.A., Squeeze flow of Bingham plastics, J. Non-Newtonian Fluid Mech. 100, 165 (2001)

[10] Estellé P., Lanos C., Squeeze flow of Bingham fluids under slip with friction boundary condition, Rheol. Acta 46(3), 397 (2007)

[11] Delhaye N., Poitou A., Chaouche M.: Squeeze flow of highly concentrated suspensions of spheres, J. Non-Newtonian Fluid Mech. 94, 67-74 (2000)

[12] Collomb J., Chaari F., Chaouche M.: Squeeze flow of concentrated suspensions of spheres in Newtonian and shear thinning fluids, J. Rheol. 48(2), 405-416 (2004)

[13] J.D. Sherwood, Liquid-solid relative motion during squeeze flow of pastes: J. Non-Newtonian Fluid Mech. 104, 1-32 (2002)

[14] Roussel N., Lanos C., Mélinge Y.: Induced heterogeneity in saturated flowing granular media, Powder Tech. 138(1), 68$72(2003)$

[15] Roussel N., Lanos C.: Particle fluid separation in shear flow of dense suspensions: experimental measurement on squeezed clay pastes, Appl. Rheol. 14 (5), 256-265 (2004)

[16] Toutou Z., Roussel N., Lanos C.: The squeezing test: a tool to identify firm cement-based material's rheological behaviour and evaluate their extrusion ability, Cement and Concrete Research 35(10), 1891-1899 (2005)

[17] See H., Advances in measuring linear viscoelastic properties using novel deformation geometries and fourier transform techniques, Korea-australian Rheology Journal 13(2), 67-81 (2001)

[18] Grosso M., Crescitelli S., Somma E., Vermant J., Moldenares P., Maffettone P.L., Prediction and observation of sustained oscillations in a sheared liquid crystalline polymer, Phys. Rev. Letter 90(9), 1-4 (2003)

[19] Leblanc J.L., Fourier transform rheology on gum elastomers, Journal of Appl. Polym. Sci. 89, 1101-1115 (2003)

[20] Kadau D., Schwesig D., Theuerkauf J., Wolf D.E.: Influence of particle elasticity in shear testers, Granular Matter 8, 3540 (2006)

[21] Servais C., Jones R., Roberts I., The influence of particle size distribution on the processing of food, J. Food Eng. 51, 201-208 (2002)

[22] Estellé P., Lanos C., Mélinge Y., Servais C.: On the optimisation of a texture analyser in squeeze flow geometry, Measurement 39, 771-777 (2006) 


\section{Figure captions}

Figure 1. Squeezing flow geometry

Figure 2. Particle size distribution of spheres

Figure 3. Shear flow curve of the colloidal gel

Figure 4. Evolution of the squeeze force $\mathrm{F}$ as a function of sample gap on plate radius ratio for different suspension concentrations and colloidal gel - compression velocity $8 \mathrm{~mm} \cdot \mathrm{s}^{-1}$

Figure 5. PSD evolution versus frequency for a $48.5 \%$ concentrated suspension squeezed at $0.1 \mathrm{~mm} . \mathrm{s}^{-1}-$ Influence of $\mathrm{T}$ value: (a) $\mathrm{T}=50$ points, (b) $\mathrm{T}=100$ points, (c) $\mathrm{T}=256$ points. Each line corresponds to PSD of windowed fluctuating force signal ; PSD increases as the sample height decreases.

Figure 6. Fluctuating force component evolution during the compression of a $48.5 \%$ dilute concentrated suspension squeezed at $0.1 \mathrm{~mm} . \mathrm{s}^{-1}$

Figure 7. PSD evolution during upper plate displacement without sample contact

Figure 8. PSD evolution in function of frequency of $48.5 \%$ concentrated suspension squeezed at $0.1 \mathrm{~mm} . \mathrm{s}^{-1}-$ (a) compression test beginning ; (b) compression test end. Each line corresponds to PSD of windowed fluctuating force signal ; PSD increases as the sample height decreases.

Figure 9. $\mathrm{PSD}_{\mathrm{a}}$ evolution versus averaged sample height $\mathrm{h}_{\mathrm{a}}$ for different concentrated suspension of spheres squeezed at $8 \mathrm{~mm} \cdot \mathrm{s}^{-1}$

Figure 10. $\mathrm{PSD}_{\mathrm{a}}$ evolution versus averaged sample height $\mathrm{h}_{\mathrm{a}}$ for $48.5 \%(\diamond)$ and $82.5 \%(0)$ concentrated suspensions of spheres squeezed at $0.1 \mathrm{~mm} \cdot \mathrm{s}^{-1}$ 


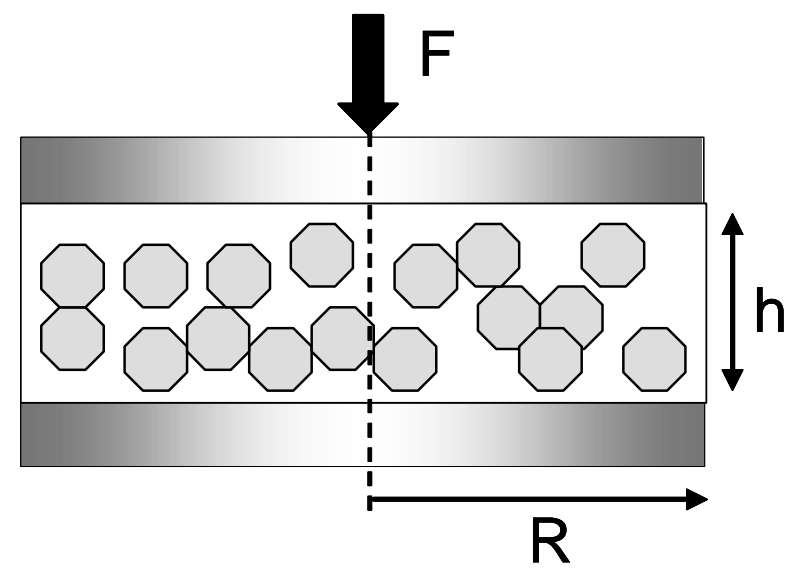

Figure 1. Squeezing flow geometry 


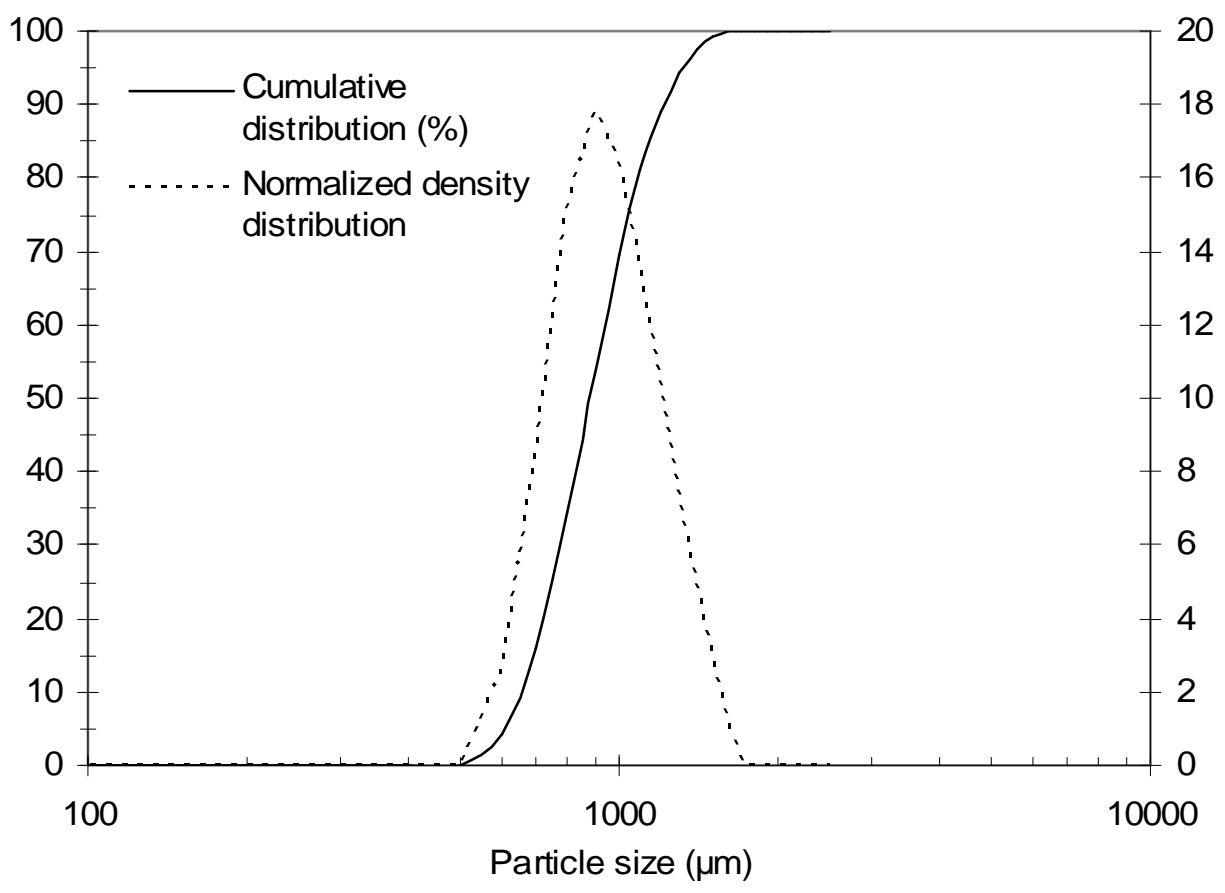

Figure 2. Particle size distribution of spheres 


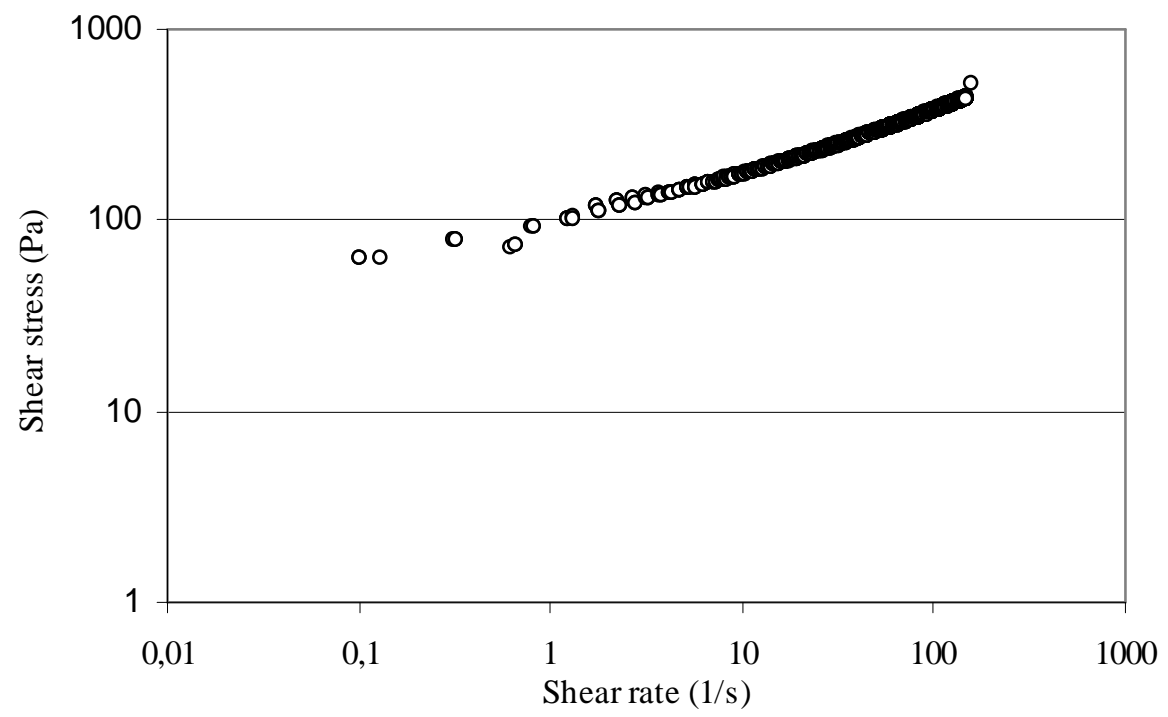

Figure 3. Shear flow curve of the colloidal gel 


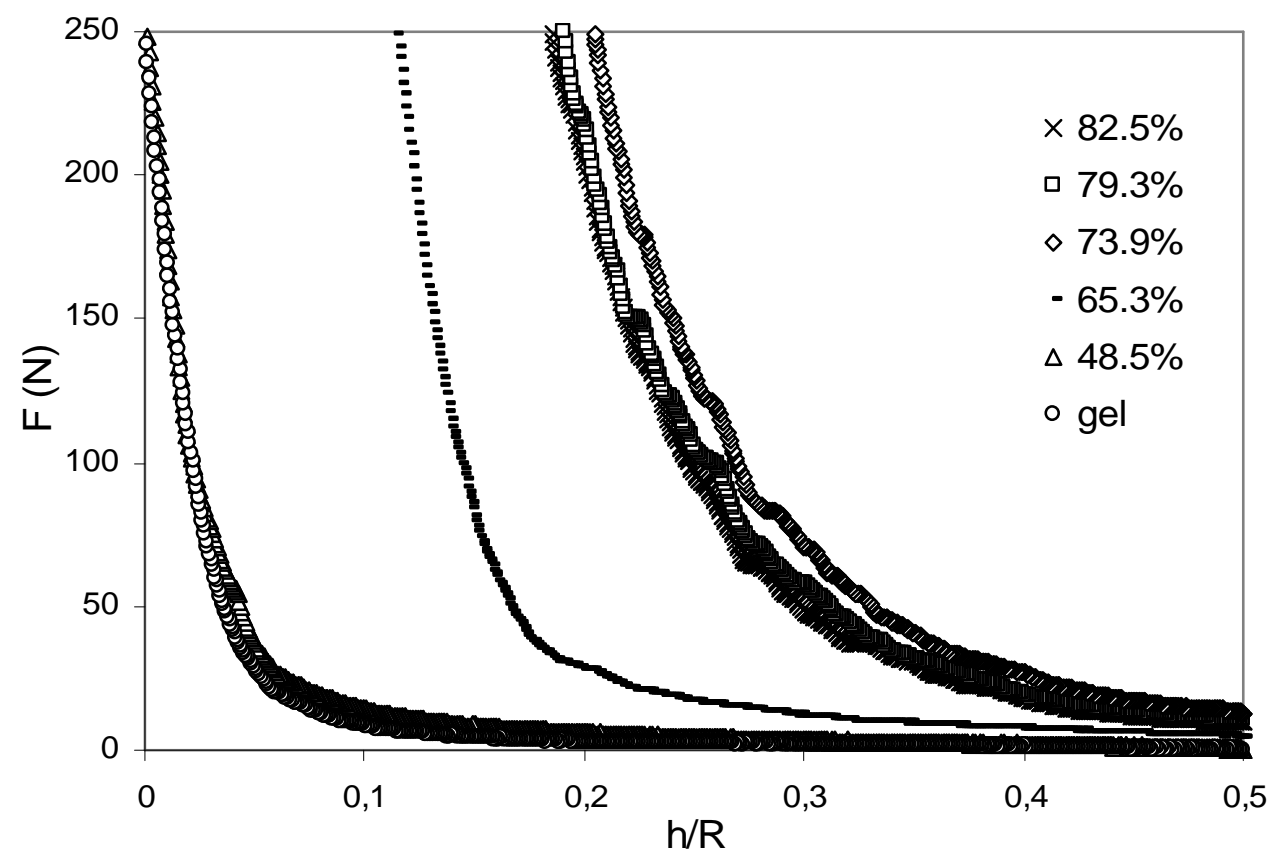

Figure 4.

Evolution of the squeeze force $\mathrm{F}$ as a function of sample gap on plate radius ratio for different suspension concentrations and colloidal gel - compression velocity $8 \mathrm{~mm} . \mathrm{s}^{-1}$ 


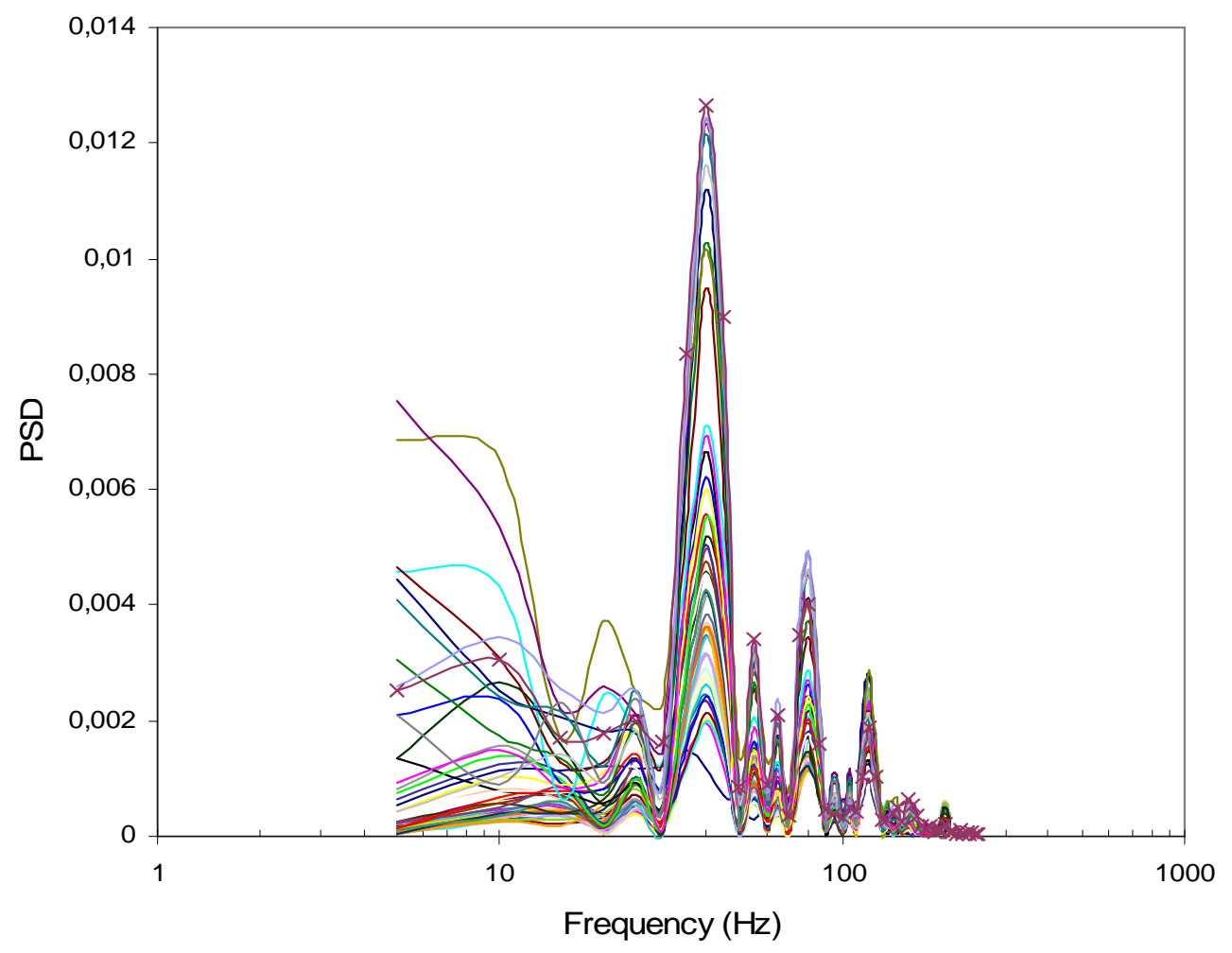

(a)

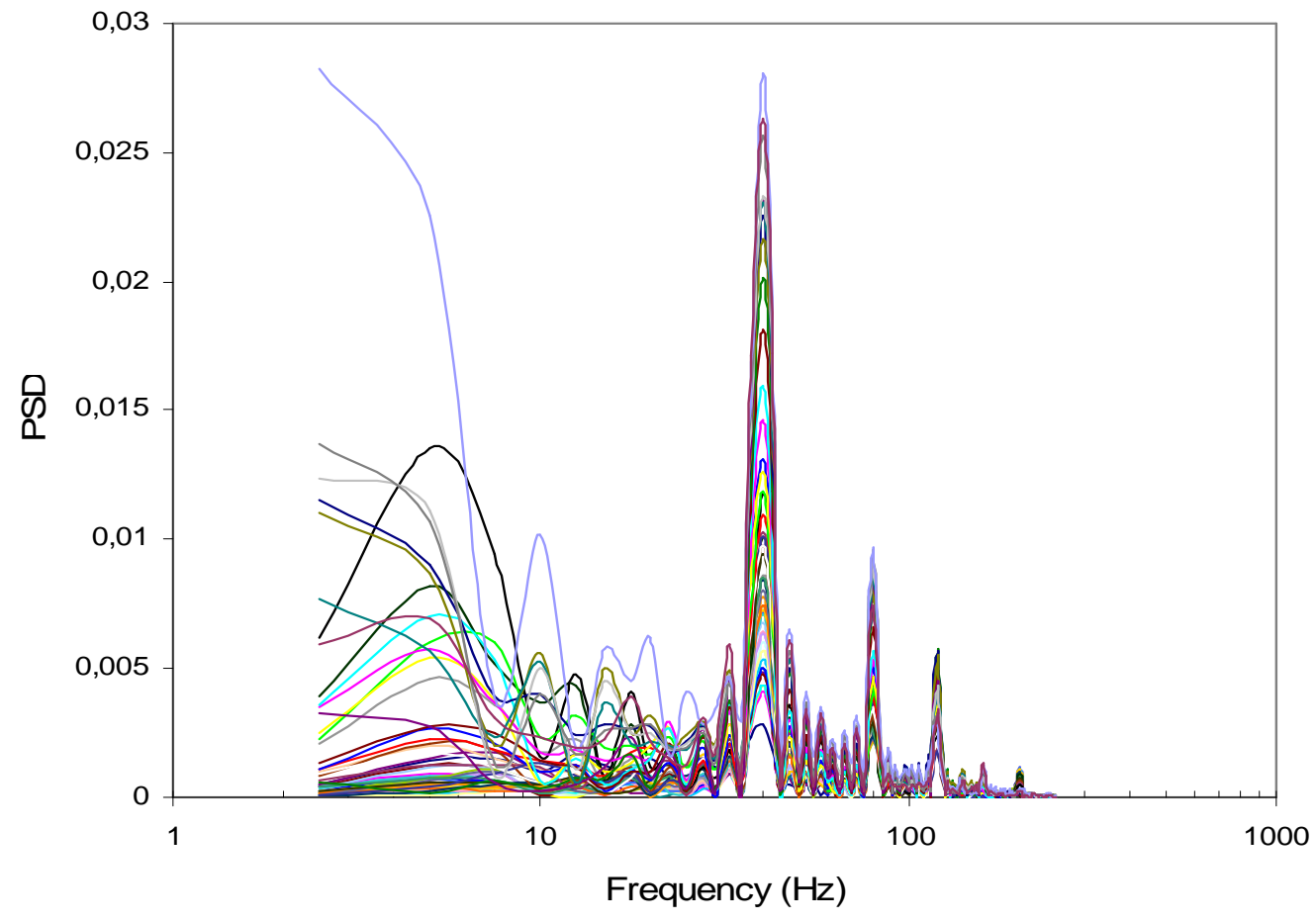

(b) 


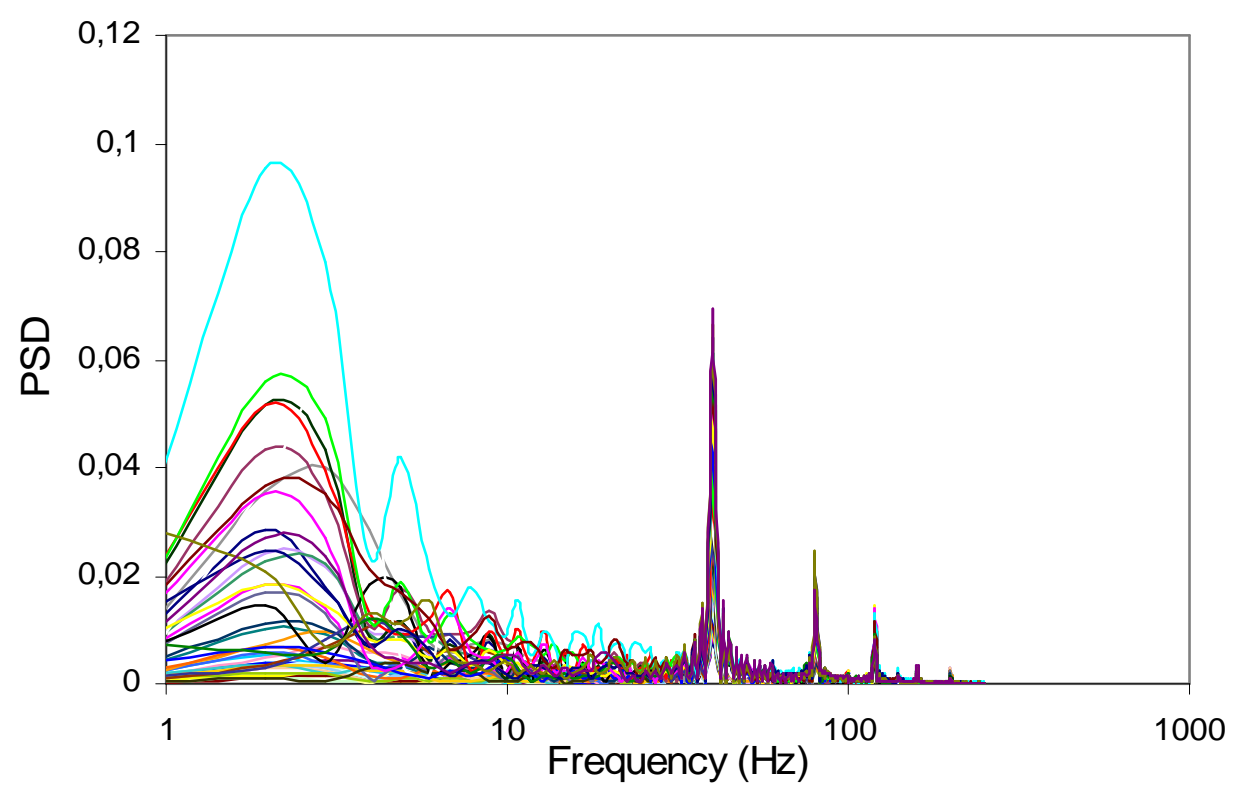

(c)

Figure 5. PSD evolution versus frequency for a $48.5 \%$ concentrated suspension squeezed at $0.1 \mathrm{~mm} . \mathrm{s}^{-1}-$ Influence of $\mathrm{T}$ value: (a) $\mathrm{T}=50$ points, (b) $\mathrm{T}=100$ points, (c) $\mathrm{T}=256$ points. Each line corresponds to $\mathrm{PSD}$ of windowed fluctuating force signal ; PSD increases as the sample height decreases. 


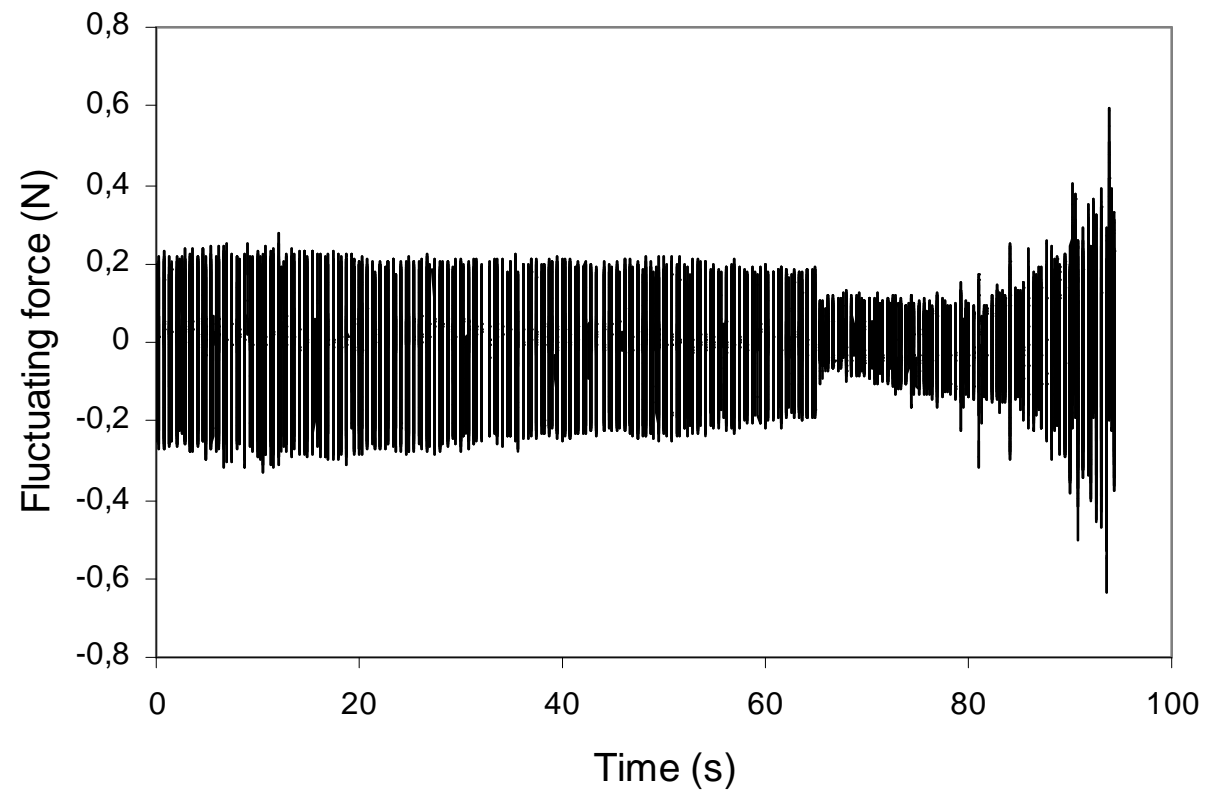

Figure 6. Fluctuating force component evolution during the compression of a $48.5 \%$ dilute concentrated suspension squeezed at $0.1 \mathrm{~mm} \cdot \mathrm{s}^{-1}$ 


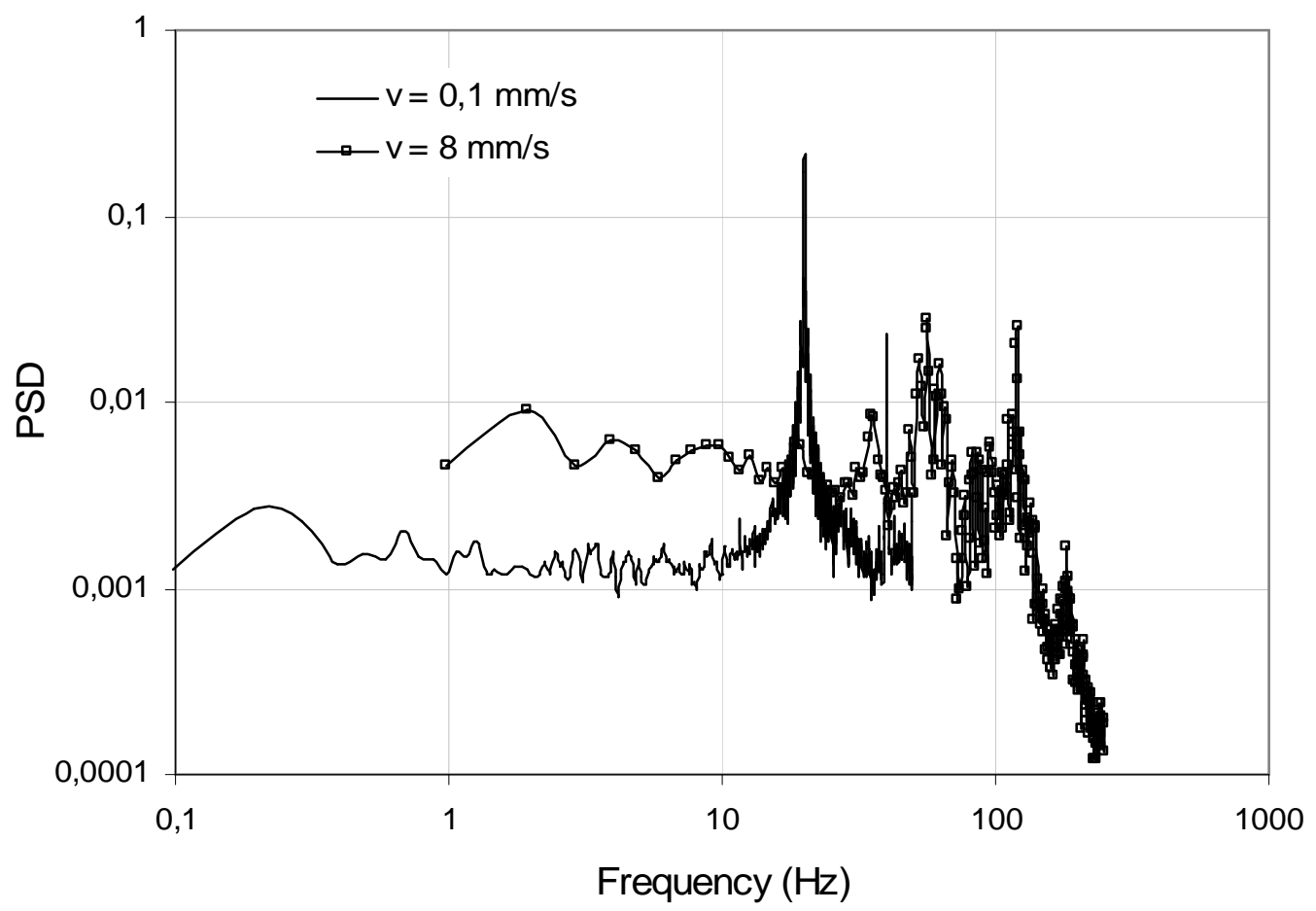

Figure 7. PSD evolution during upper plate displacement without sample contact 


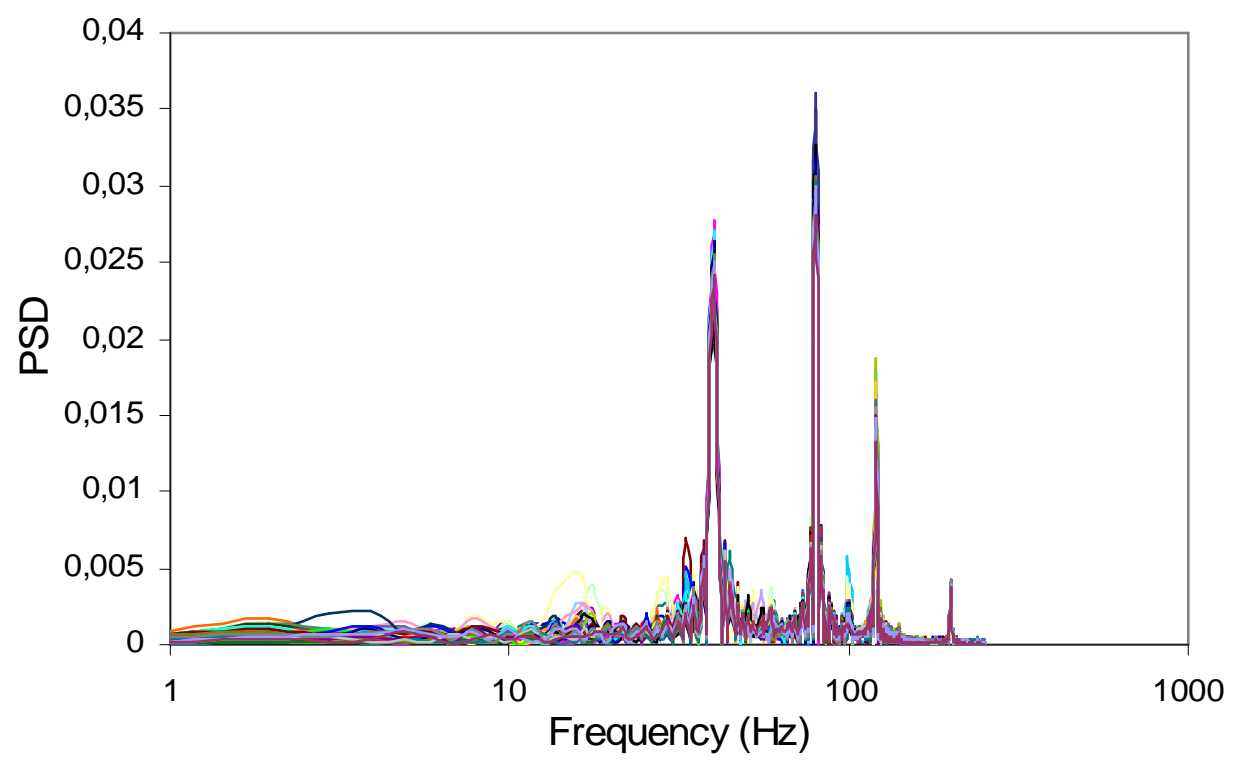

(a)

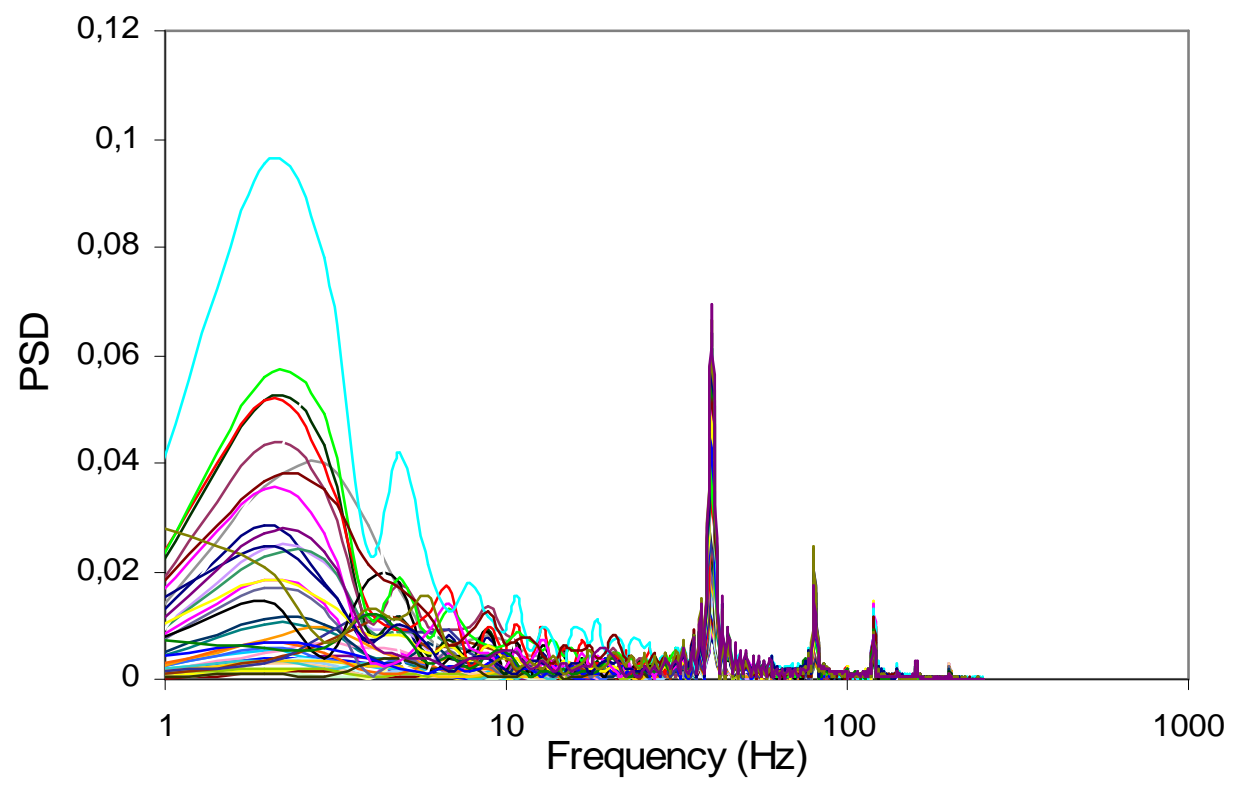

(b)

Figure 8. PSD evolution in function of frequency of $48.5 \%$ concentrated suspension squeezed at $0.1 \mathrm{~mm} . \mathrm{s}^{-1}-(\mathrm{a})$ compression test beginning; (b) compression test end. Each line corresponds to PSD of windowed fluctuating force signal ; PSD increases as the sample height decreases. 


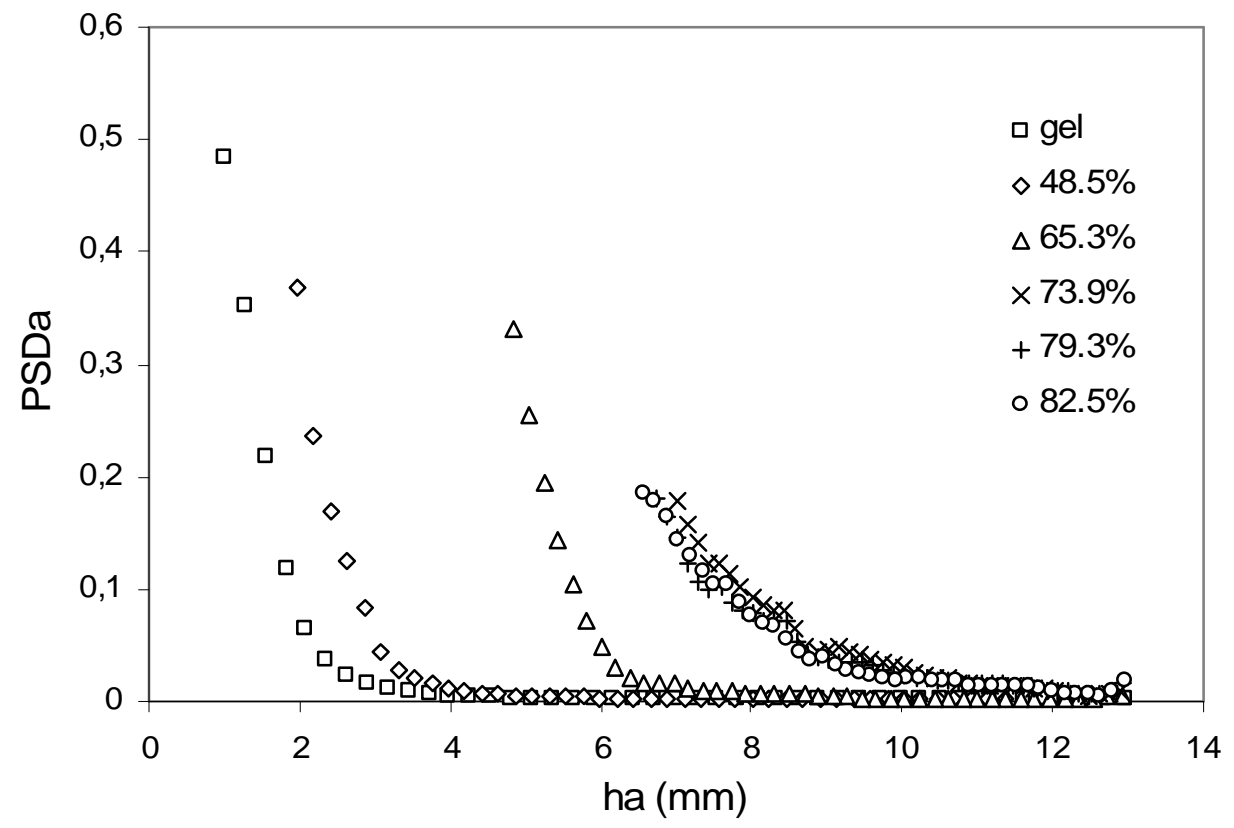

Figure 9. PSD $_{a}$ evolution versus averaged sample height $h_{a}$ for different concentrated suspension of spheres squeezed at $8 \mathrm{~mm} . \mathrm{s}^{-1}$ 


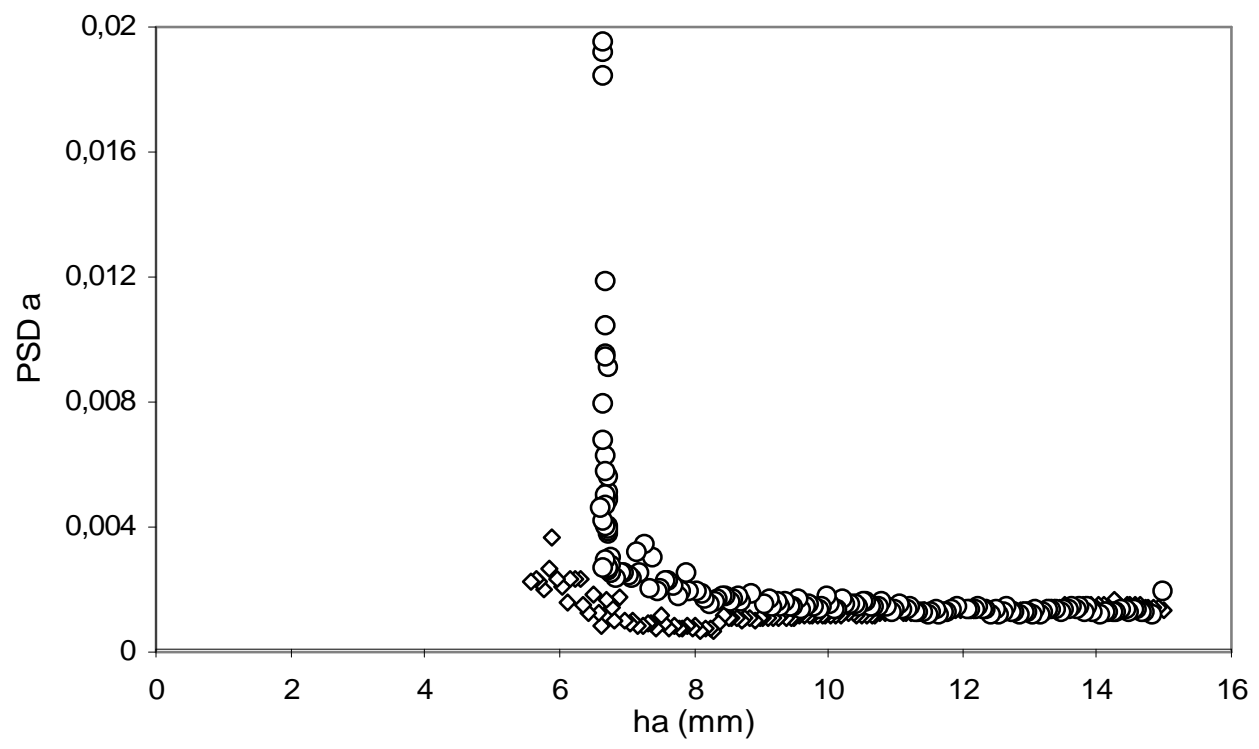

Figure 10. $\mathrm{PSD}_{\mathrm{a}}$ evolution versus averaged sample height $\mathrm{h}_{\mathrm{a}}$ for $48.5 \%(\diamond)$ and $82.5 \%(0)$ concentrated suspensions of spheres squeezed at $0.1 \mathrm{~mm} . \mathrm{s}^{-1}$ 